\title{
Metal-Sulfide Catalysts Derived from Lignosulfonate and their Efficient Use in Hydrogenolysis
}

\author{
Sijie Liu, ${ }^{[a, b]}$ Antoine P. van Muyden, ${ }^{[a]}$ Lichen Bai $^{[a]}$ Xinjiang Cui, ${ }^{[a]}$ Zhaofu Fei, ${ }^{[a]}$ Xuehui Li, $^{*[b]}$ \\ Xile $\mathrm{Hu}^{*{ }^{*[a]}}$ and Paul J. Dyson ${ }^{*[a]}$
}

\begin{abstract}
Catalytic lignosulfonate valorization is hampered by the in situ liberation of sulfur that ultimately poisons the catalyst. To overcome this limitation, metal sulfide catalysts were developed that are able to cleave the $\mathrm{C}-\mathrm{O}$ bonds of lignosulfonate and are resistant to sulfur poisoning. The catalysts were prepared by using the lignosulfonate substrate as a precursor to form well-dispersed carbon-supported metal (Co, Ni, Mo, CoMo, NiMo) sulfide catalysts. Following optimization of the reaction conditions employing a model substrate, the catalysts were
\end{abstract}

used to generate guaiacyl monomers from lignosulfonate. The Co catalyst was able to produce $23.7 \mathrm{mg}$ of 4-propylguaiacol per gram of lignosulfonate with a selectivity of $84 \%$. The catalysts operated in water and could be recycled and reused multiple times. Thus, it was demonstrated that an inexpensive, sulfur-tolerant catalyst based on an earth-abundant metal and lignosulfonate efficiently catalyzed the selective hydrogenolysis of lignosulfonate in water in the absence of additives.

\section{Introduction}

Biomass has been extensively investigated as a source of renewable fuels and chemicals, ${ }^{[1-3]}$ with the development of competitive biorefineries requiring efficient processes able to valorize all components in biomass. ${ }^{[1]}$ The utilization of cellulose and hemicellulose to produce fuels and chemicals is a mature technology, ${ }_{1}^{[4-6]}$ whereas utilization of the more recalcitrant biopolymer, lignin, remains challenging despite excellent progress. ${ }^{[7]}$ Consequently, lignin is often considered a waste material, which is usually burned to recover heat, ${ }^{[8,9]}$ and its valorization continues to be widely studied. ${ }^{[1,7]}$ Various lignins arise from different biomass treatment protocols, and, in general, most lignins are insoluble in common solvents, severely inhibiting efforts to valorize lignin..$^{[1,10]}$

Lignosulfonate (LS) is a typical highly condensed lignin waste from the pulping industry produced in approximately 50 million tons per year ${ }^{[9]}$ and easily dissolves in water. LS is often used as a cheap and renewable material ${ }^{[11,12]}$ for plasticizers, ${ }^{[13,14]}$ corrosion inhibitors, ${ }^{[16]}$ surfactants, ${ }^{[17]}$ dispersants, ${ }^{[18]}$ membranes, ${ }^{[19]}$ and as a carbonaceous matrix for catalysts and

[a] S. Liu, A. P. van Muyden, L. Bai, Dr. X. Cui, Dr. Z. Fei, Prof. X. Hu,

Prof. P. J. Dyson

Institute of Chemical Sciences and Engineering (ISIC)

École Polytechnique Fedérale de Lausanne (EPFL)

1015 Lausanne (Switzerland)

E-mail:pjd@epfl.ch

Xile.Hu@epfl.ch

[b] S. Liu, Prof. X. Li

Laboratory of Pulp and Paper Engineering

South China University of Technology

Guangzhou, Guangdong, 510640 (P.R. China)

E-mail: cexhli@scut.edu.cn

$\square$ Supporting Information and the ORCID identification number(s) for the

(iD

author(s) of this article can be found under:

https://doi.org/10.1002/cssc.201900677. electrodes. ${ }^{[20-22]}$ The sulfur content in LS typically varies from $3-6 \%$, depending on the pulping process, ${ }^{[20,23]}$ and therefore it has been used in the synthesis of S-doped porous carbon materials and was successfully applied in the acetalization of glycerol $^{[20]}$ and as a cathode in lithium-sulfur batteries. ${ }^{[24]}$ Catalytic fractionation of LS into bulk chemicals has also been widely investigated, and vanillin is already produced on an industrial scale through LS oxidation. ${ }^{[25-27]}$ Hydrogenolysis and hydrogenation are another promising route to valorize $L S$, producing aromatic and aliphatic derivatives depending upon the catalyst used and the reaction conditions. ${ }^{[23,28]}$ However, the sulfur in LS tends to poisons most catalysts, ${ }^{[28,29]}$ leading to rapid catalyst deactivation of hydrogenolysis catalysts that typically operate in organic solvents. ${ }^{[28,30]}$

Transition-metal-sulfide catalysts based on $\mathrm{Co}^{\left[{ }^{[1-34]}\right.} \mathrm{Mo}^{[33,35]}$ and $\mathrm{Ni}^{[35,36]}$ have been intensively studied in hydrogenation, hydrodeoxygenation (HDO), and hydrodesulfurization (HDS) of petrochemicals and in the pyrolysis of bio-oil, owing to their high activity and low cost. Bimetallic CoMo- and NiMo-sulfide catalysts were applied recently in the hydrotreatment of lignin and lignin model compounds under solvent-free conditions ${ }^{[37]}$ and in subcritical methanol, ${ }^{[38]}$ with the catalysts exhibiting good activity towards the cleavage of $\mathrm{C}-\mathrm{O}$ bonds. Metalsulfide catalysts immobilized on acidic supports (i.e., $\mathrm{SiO}_{2}$, $\mathrm{Al}_{2} \mathrm{O}_{3}$ ) result in rapid coke formation, ${ }^{[34-36,39]}$ and therefore metal oxides are often replaced by carbon support materials. ${ }^{[40-43]}$ Carbon-supported metal-sulfide catalysts have been obtained from a traditional multistep process comprising incipient wetness, co-impregnation on activated carbon, and sulfidization in a subsequent step under a flow of $\mathrm{H}_{2} \mathrm{~S} \mathrm{H}_{2}{ }^{[36,44,45]}$ or through heat treatment with sulfur-containing organics, that is, dimethylsulfide ${ }^{[37]}$ or thiourea. ${ }^{[2]}$ To bypass the sulfidation step, we decided to use LS as precursor to synthesize highly dis- 
persed metal-sulfide catalysts through pyrolysis of LS impregnated with metal acetate salts. The resulting catalysts were evaluated as hydrogenolysis catalysts because well-dispersed catalysts such as single-atom catalysts are unable to hydrogenate aromatic rings, ${ }^{[46]}$ and therefore should lead to high selectivities toward hydrogenolysis. Moreover, the prepared catalysts are naturally sulfur-tolerant owing to the presence of metal-sulfide bonds.

\section{Results and Discussion}

The metal-sulfide catalysts were prepared through dispersion of the appropriate metal acetate salts with $\mathrm{Mg}(\mathrm{OH})_{2}$ onto $\mathrm{LS}$ in methanol ${ }^{[46]}$ followed by pyrolysis for $4 \mathrm{~h}$ at different temperatures under $\mathrm{N}_{2}$ (Scheme 1), to afford the appropriate metal sulfide and $\mathrm{MgO}$. The $\mathrm{MgO}$ was subsequently removed by washing the solid with $\mathrm{HNO}_{3}$ (see the Experimental Section for full details and Table 1 for the structural properties of the catalysts).

Table 1. Surface area, pore volume, and acidic properties of the catalysts calcined at $700^{\circ} \mathrm{C}$.

\begin{tabular}{|lllllll|} 
Catalyst & $\begin{array}{l}\mathrm{Metal}^{[\mathrm{a}]} \\
{\left[\mathrm{mmol} \mathrm{g}^{-1}\right]}\end{array}$ & $\begin{array}{l}\mathrm{S}^{[\mathrm{b}]} \\
{\left[\mathrm{mmol} \mathrm{g}^{-1}\right]}\end{array}$ & $\begin{array}{l}\mathrm{S}_{\text {excess }} \\
{[\mathrm{eq} .]}\end{array}$ & $\begin{array}{l}\mathrm{SA}^{[\mathrm{c}]} \\
{\left[\mathrm{m}^{2} \mathrm{~g}^{-1}\right]}\end{array}$ & $\begin{array}{l}\mathrm{VP}_{\text {total }}[\mathrm{c}] \\
{\left[\mathrm{cm}^{3} \mathrm{~g}^{-1}\right]}\end{array}$ & $\begin{array}{l}\text { Acid sites } \\
{\left[\mu \mathrm{mol} \mathrm{g}^{-1}\right]}\end{array}$ \\
\hline $\mathrm{Co}_{3} \mathrm{~S}_{4} / \mathrm{C}$ & 56 & 168 & 1.3 & 379 & 0.41 & 165 \\
$\mathrm{NiS} / \mathrm{C}$ & 61 & 221 & 2.6 & 560 & 0.77 & 349 \\
$\mathrm{MoS}_{2} / \mathrm{C}$ & 37 & 165 & 1.2 & 630 & 0.93 & 196 \\
$\mathrm{Co}_{3} \mathrm{MoS}_{6} / \mathrm{C}$ & 62 & 162 & -0.4 & 485 & 0.88 & 196 \\
$\mathrm{NiMoS}_{3} / \mathrm{C}$ & 47 & 190 & 0.4 & 412 & 0.50 & 219 \\
$\mathrm{~S} / \mathrm{C}$ & - & 180 & - & 571 & 0.68 & 150 \\
\hline
\end{tabular}

[a] Determined by inductively coupled plasma atomic emission spectroscopy (ICP-AES). [b] Determined by elemental analysis. [c] Determined by physisorption of $\mathrm{N}_{2}$. SA = surface area, $\mathrm{VP}_{\text {total }}=$ total pore volume. [d] Determined by chemisorption of $\mathrm{NH}_{3}$.

The metal loading varies from 3.3 to $3.6 \mathrm{wt} \%$ with the exception of $\mathrm{Co}_{3} \mathrm{MoS}_{6} / \mathrm{C}$, which has a higher metal content of $5.0 \mathrm{wt} \%$. The sulfur content exceeds that of the metals except for $\mathrm{CO}_{3} \mathrm{MoS}_{6}$, which implies, as expected, that more than one sulfur atom interacts with the metal atoms. Moreover, X-ray photoelectron spectroscopy (XPS) analysis of the $\mathrm{S}$ region shows that sulfur is present in both sulfide and sulfonate forms (Figure 3). The acid sites of the support material were determined by temperature-programmed desorption of ammonia ( $\mathrm{NH}_{3}$-TPD) and vary from 150 to $349 \mu \mathrm{mol} \mathrm{g}^{-1}$. In general, the utilization of LS as a precursor results in more acidic sites than in classical carbon-supported catalysts (typically 40
$100 \mu \mathrm{molg}^{-1}$ ). ${ }^{[37]}$ The $\mathrm{NH}_{3}$-TPD analysis (Figure $1 \mathrm{a}, \mathrm{b}$ ) also shows that the nickel-sulfide catalyst, NiS/C, possesses a higher number of weak acid sites than the other catalysts, which is in agreement with a computational study showing that the strength of the acid-base interaction depends on the metal ion. ${ }^{[4]}$ The surface areas of the catalysts range from 379 to $630 \mathrm{~m}^{2} \mathrm{~g}^{-1}$ and the pore volumes vary from 0.4 to $0.9 \mathrm{~cm}^{3} \mathrm{~g}^{-1}$, which is in line with the carbon-supported metal-sulfide catalysts prepared with $\mathrm{H}_{2} \mathrm{~S}$ or dimethyl disulfide. ${ }^{[41]}$ XRD patterns of the metal-sulfide catalysts are similar to the Sulphur-doped carbon $(\mathrm{S} / \mathrm{C}$ ) material (Figure $1 \mathrm{c}, \mathrm{d}$ ), with a broad peak centered at approximately $25^{\circ}$ corresponding to amorphous carbon (002). Sharpe peaks characteristic of crystalline structures are absent, except in the XRD patterns of the Ni-containing catalysts (i.e., $\mathrm{NiS} / \mathrm{C}$ and $\mathrm{NiMoS}_{3} / \mathrm{C}$ ), which exhibit some crystallinity attributable to $\alpha$-NiS nanoparticles. ${ }^{[48-50]}$ The catalysts were further characterized by TEM (Figure 2). The bright-field image of $\mathrm{Co}_{3} \mathrm{~S}_{4} / \mathrm{C}$ (Figure $2 \mathrm{a}$, left) reveals a porous amorphous carbon structure. The enlarged images (Figure $2 b, c$, left) indicate that distinct Co nanoparticles are not present in the carbon matrix. Energy dispersive X-ray spectroscopy (EDX) mapping was recorded in high-angle annular dark-field scanning transmission electron microscopy (HAADF-STEM) mode and confirmed that the material consists mainly of homogeneously dispersed $\mathrm{C}, \mathrm{O}$, $\mathrm{S}$, and Co (Figure $2 \mathrm{~d}$, left) atoms. Spherical aberration-corrected HAADF-STEM (Figure $2 \mathrm{e}-\mathrm{g}$, left) was used to observe the catalyst at atomic resolution. The well-dispersed bright dots in the HAADF-STEM images indicate the presence of both single Co atoms (Figure $2 \mathrm{f}$, left) or small clusters of Co atoms (Figure $2 \mathrm{~g}$, left). The TEM images of $\mathrm{MoS}_{2} / \mathrm{C}$ are similar to those of the $\mathrm{CO}_{3} \mathrm{~S}_{4} / \mathrm{C}$ catalyst (Figure $\mathrm{S} 2$ in the Supporting Information).

The TEM images of the NiS/C catalyst confirmed the presence of NiS nanoparticles (Figure 2, right). The enlarged image (Figure $2 \mathrm{~b}$, right) shows that the NiS nanoparticles are anchored on the porous carbon support. High-resolution TEM (HRTEM) images confirm the structure of the crystals (Figure $2 c, d$, right) with interplanar spacing of 0.195 and $0.293 \mathrm{~nm}$ corresponding to the $(101)$ and (110) planes of $\alpha-\mathrm{NiS}$, respectively. ${ }^{[51]}$ The blue region (Figure $2 \mathrm{e}$, right) highlights the presence of many NiS nanoparticles. EDX mapping analysis revealed that the nanoparticles are composed mainly of $\mathrm{S}$ and $\mathrm{Ni}$ (Figure $2 \mathrm{f}$, right). The TEM images of the bimetallic-sulfide catalysts are presented in Figures S3 and S4 in the Supporting Information, and they have similar characteristics to the monometallic catalysts (i.e., $\mathrm{Co}_{3} \mathrm{~S}_{4} / \mathrm{C}$ catalysts are well dispersed whereas NiS/C catalysts form $\alpha$-NiS nanoparticles).

XPS was used to determine the surface chemical compositions of the catalysts (Figure 3 ). The Co $2 p$ region shows the

\section{Lignosulfonate}

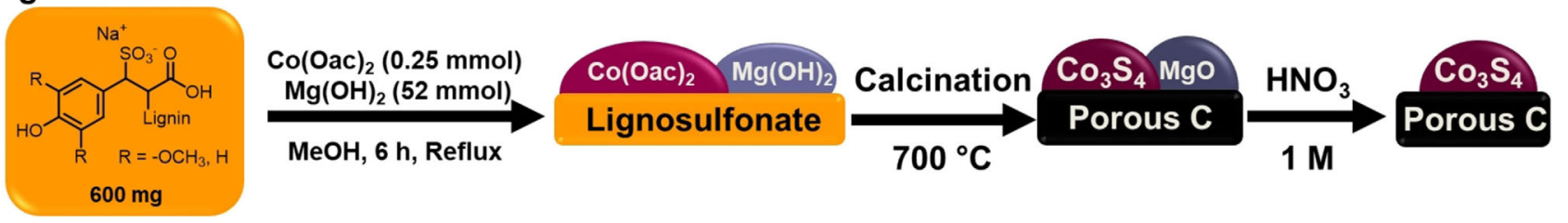

Scheme 1. Illustration of the synthetic route used to prepare the $\mathrm{CO}_{3} \mathrm{~S}_{4} / \mathrm{C}$ catalyst. 

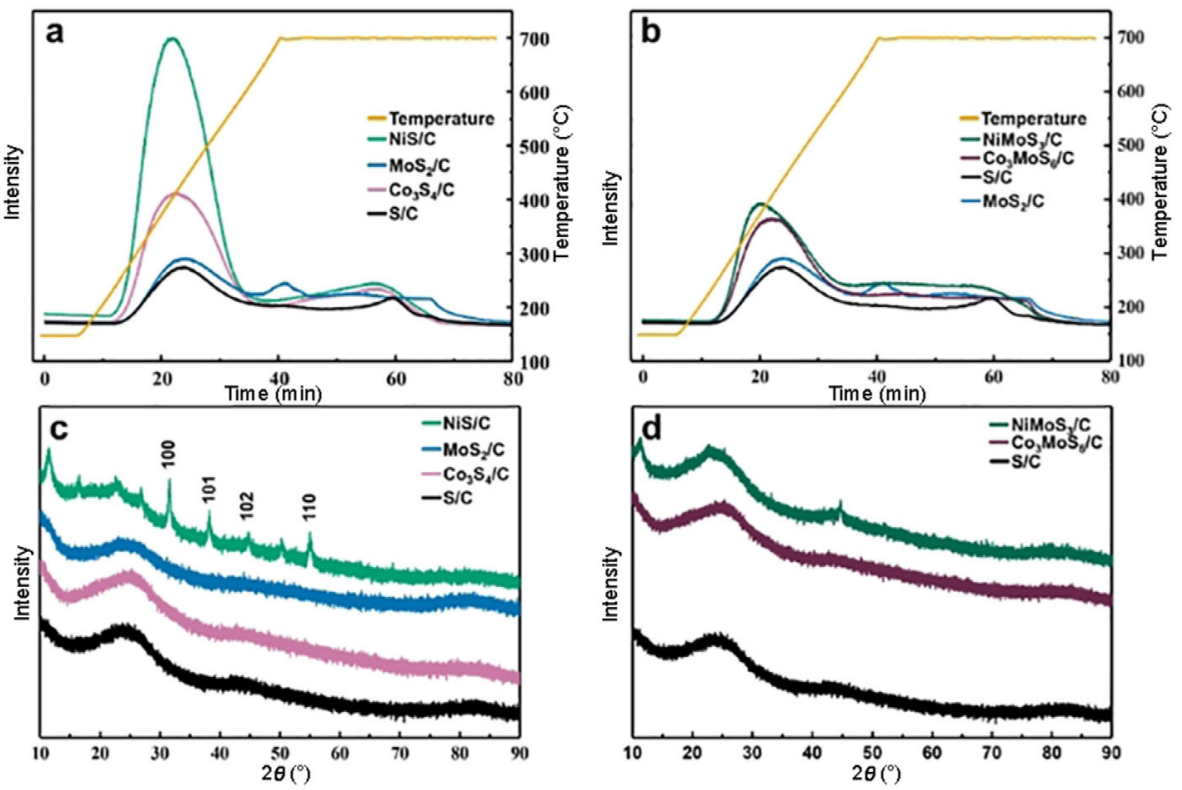

Figure 1. (a) $\mathrm{NH}_{3}$-TPD analysis of the monometallic-sulfide catalysts. (b) $\mathrm{NH}_{3}$-TPD analysis of the bimetallic-sulfide catalysts. The support ( $\mathrm{S} / \mathrm{C}$ ) and the MoS $/ \mathrm{C}$ catalyst are shown in both figures for comparison. (c) XRD patterns of the monometallic-sulfide catalysts. (d) XRD patterns of the bimetallic-sulfide catalysts.

\section{$\mathrm{Co}_{3} \mathrm{~S}_{4} / \mathrm{C}$}

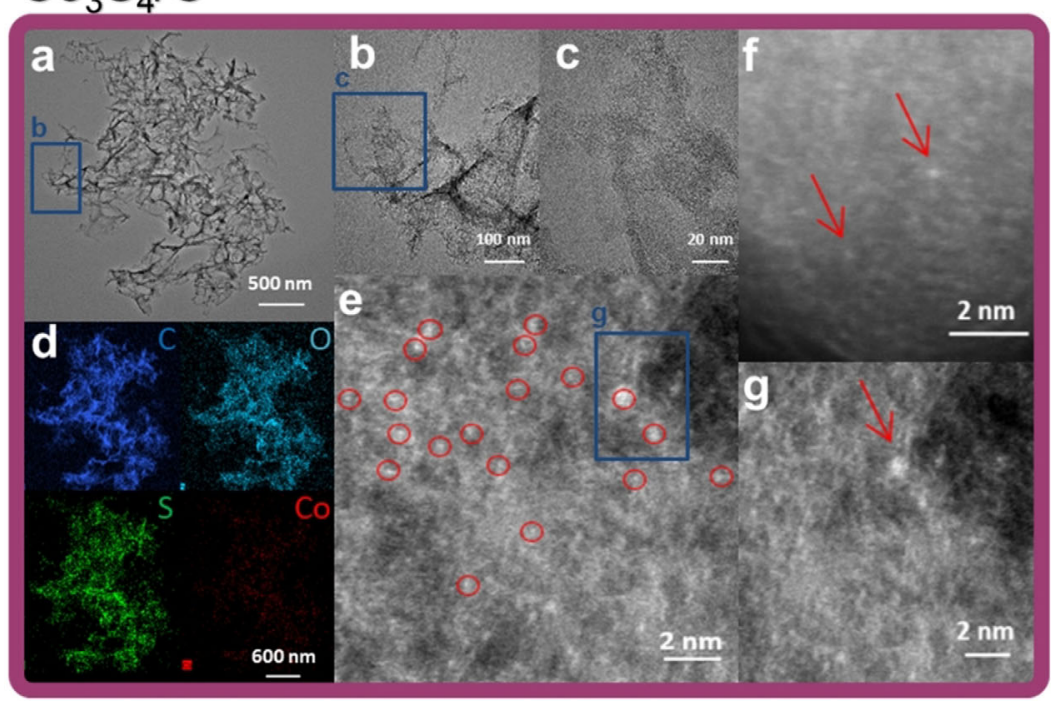

\section{$\mathrm{NiS} / \mathrm{C}$}

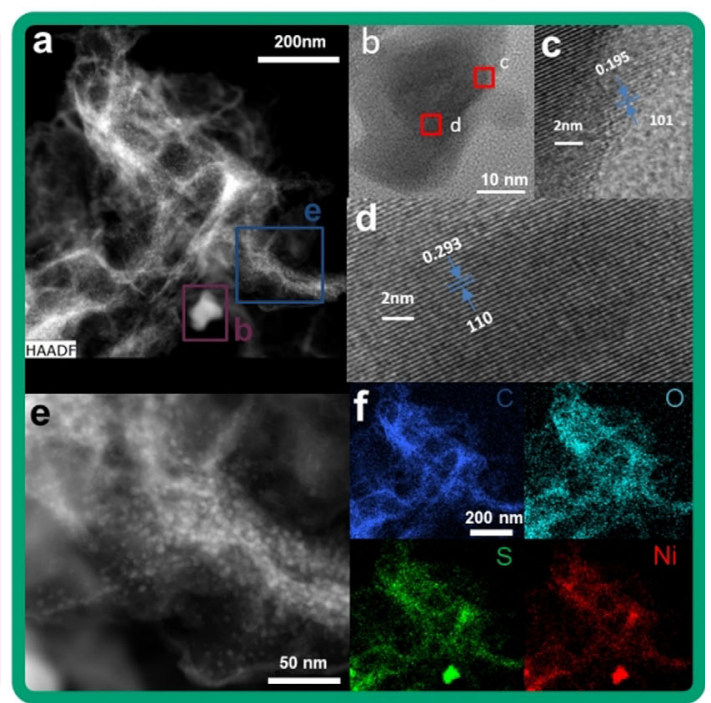

Figure 2. Purple rectangle: (a) Bright-field TEM image of the $\mathrm{Co}_{3} \mathrm{~S}_{4} / \mathrm{C}$ catalyst. (b) Enlarged image corresponding to the blue rectangle in (a). (c) Enlarged image corresponding to the blue rectangle in (b). (d) EDX mapping. (e) Spherical aberration-corrected HAADF-STEM image. (f) Spherical aberration-corrected HAADF-STEM image showing single atoms. (g) Enlarged region of (e) showing the presence of clusters. Green rectangle: (a) Dark-field TEM image of the NiS/C catalyst. (b) HRTEM enlarged image corresponding to the red rectangle in (a). (c) HRTEM enlarged image corresponding to the blue rectangle in (a).

(d) HRTEM of red squares in (b) (with lattices fringes corresponding to $\alpha$-NiS). (e) HAADF images of the blue square in (a). (f) EDX mapping.

presence of Co in both +2 and +3 oxidation states ${ }^{[50]}$ and a characteristic peak of $\mathrm{CoSO}_{4}$ resulting from the surface oxidation of Co-S species $(785 \mathrm{eV})$. The two oxidation states suggest that cobalt clusters of the formula $\mathrm{CO}_{3} \mathrm{~S}_{4}$ are present. Nickel is in the +2 oxidation state and shows two distinct species that may be attributed to $\mathrm{NiS}$ and $\mathrm{NiSO}_{4} \cdot{ }^{[52]} \mathrm{Mo}$ is only observed as $\mathrm{Mo}^{4+}$ linked to either $\mathrm{S}$ or $\mathrm{O}$. To rule out the possibility of metal oxides, the $\mathrm{O} 1 \mathrm{~s}$ region was examined, and only peaks corresponding to $\mathrm{C}-\mathrm{O}$ and $\mathrm{C}=\mathrm{O}$ carbon are present (at 532.5 and $533.7 \mathrm{eV}$, respectively). The $\mathrm{S} 2 \mathrm{p}$ region confirms the presence of sulfide bonded to metals and to oxygen as sulfate ${ }^{[52]}$ with the latter attributed to the excess sulfur atoms presents in the LS support material and surface oxidation of the metal sulfides into the corresponding sulfate. Because the Co and Mo catalysts are well dispersed, the ratio of each species varies, and the XPS experiment should be considered as 

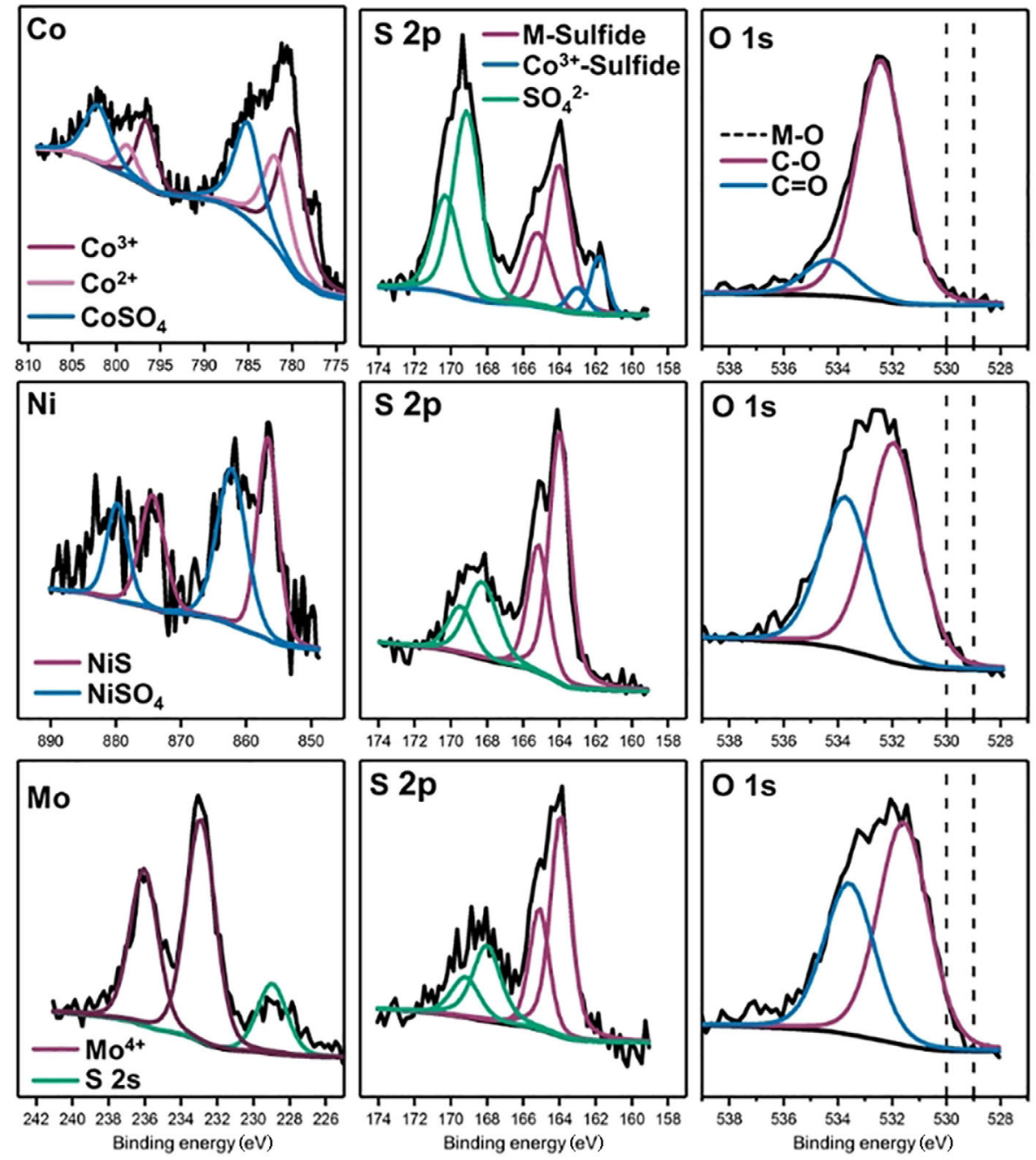

Figure 3. Left: metal region, middle: $\mathrm{S} 2 \mathrm{p}$ region, right: $\mathrm{O} 1 \mathrm{~s}$ region for the $\mathrm{Co}$ (top), $\mathrm{Ni}$ (center), and Mo (bottom) monometallic-sulfide catalysts. The dashed line in the $\mathrm{O} 1 \mathrm{~s}$ region highlights the absence of metal oxides on the surface.

qualitative. The XPS spectra of the bimetallic-sulfide species exhibit similar patterns to the monometallic-sulfide catalysts (Figure S5 in the Supporting Information).

The six catalysts were evaluated in the hydrogenolysis of 2(2-methoxyphenoxy)-1-phenylethanol (MPP-ol) at 150 and $180^{\circ} \mathrm{C}$ for $5 \mathrm{~h}$ (Figure $4 \mathrm{a}$ ). At $150^{\circ} \mathrm{C}$ (low conversion rate, Fig-

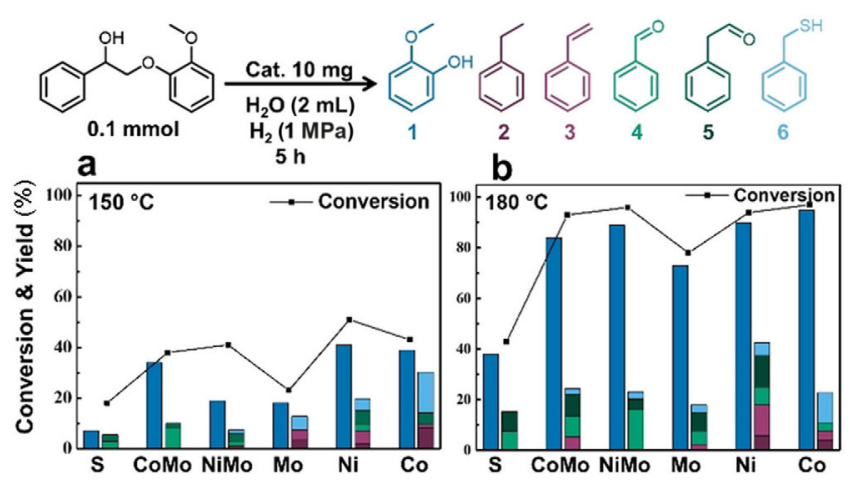

Figure 4. Conversion of the model compound and product distribution at (a) low and (b) high conversion. ure $4 \mathrm{a})$, three catalysts are reasonably active $\left(\mathrm{Co}_{3} \mathrm{~S}_{4} / \mathrm{C}, \mathrm{NiS} / \mathrm{C}\right.$, and $\mathrm{CO}_{3} \mathrm{MoS}_{6} / \mathrm{C}$ ) with conversions between $40-50 \%$. The support alone catalyzes the reaction to a modest extent owing to the presence of the weakly acidic surface sites on the support. ${ }^{[8,53]}$ The selectivity of the catalysts was assessed, and, at $180^{\circ} \mathrm{C}$ (high conversion rate, Figure $4 \mathrm{~b}$ ), all catalysts afford 1 , with the $\mathrm{CO}_{3} \mathrm{~S}_{4} / \mathrm{C}$ catalyst resulting in the highest yield of $95 \%$. Notably, $\mathrm{Co}_{3} \mathrm{~S}_{4} / \mathrm{C}$ affords more 6 than NiS/C (12 vs. $5 \%$ ), whereas the bimetallic $\left(\mathrm{CO}_{3} \mathrm{MoS}_{6} / \mathrm{C}, \mathrm{NiMoS}_{3} / \mathrm{C}\right)$ catalysts produce preferentially the aldehyde products $(\mathbf{4}, \mathbf{5})$. Styrene $(\mathbf{3})$ is produced with $\mathrm{Co}_{3} \mathrm{MoS}_{6} / \mathrm{C}$ (note that at $180^{\circ} \mathrm{C}$, the activity of $\mathrm{NiMoS}_{3} / \mathrm{C}$ is similar to $\mathrm{Co}_{3} \mathrm{MoS}_{6} / \mathrm{C}$ ). In all experiments hydrogenation of the aromatic ring is not observed. This is in agreement with the inability of small clusters and single-atom catalysts to catalyze this reaction, ${ }^{[54]}$ and, surprisingly, NiS/C and $\mathrm{NiMoS}_{3} / \mathrm{C}$ (which contain nanoparticles) also show the same selectivity. In an attempt to improve the catalyst, $\mathrm{Co}_{3} \mathrm{~S}_{4} / \mathrm{C}$ was calcined at different temperatures, and $700^{\circ} \mathrm{C}$ appears to be the optimum one (Figure S6 in the Supporting Information). We further investigated the effect of different lignin precursors (alkali lignin, Russia LS, and dealkalized lignin). The catalysts exhibit similar 
selectivities, but the conversion varies from $70-90 \%$ (Table S2, Figure S7 in the Supporting Information).

All prepared catalysts show good activities for the hydrogenolysis of MPP-ol, but leaching of the metals takes place owing to the formation of $\mathrm{H}_{2} \mathrm{~S}$ and product 6 (the $\mathrm{S}$ is derived from the catalyst support, thus allowing the metal to leach). ${ }^{[28]}$ Note that $\mathrm{H}_{2} \mathrm{~S}$ was detected at the end of the reaction (see the Experimental Section). We hypothesized that LS as substrate could prevent such a leaching mechanism because $\mathrm{H}_{2} \mathrm{~S}$ would be generated from the substrate rather than from the catalyst, thereby protecting the catalyst from decomposition. Consequently, the hydrogenolysis of LS was investigated, albeit under harsher conditions $\left(230^{\circ} \mathrm{C}, 5 \mathrm{MPa}, 10 \mathrm{~h}\right)$ than those used for the model substrate. Of the six catalysts, the $\mathrm{Co}_{3} \mathrm{~S}_{4} / \mathrm{C}$ catalyst is the most active and produces $27.9 \mathrm{mg}$ of products per gram of substrate (Figure $5 \mathrm{a}$ ). The four major products com-
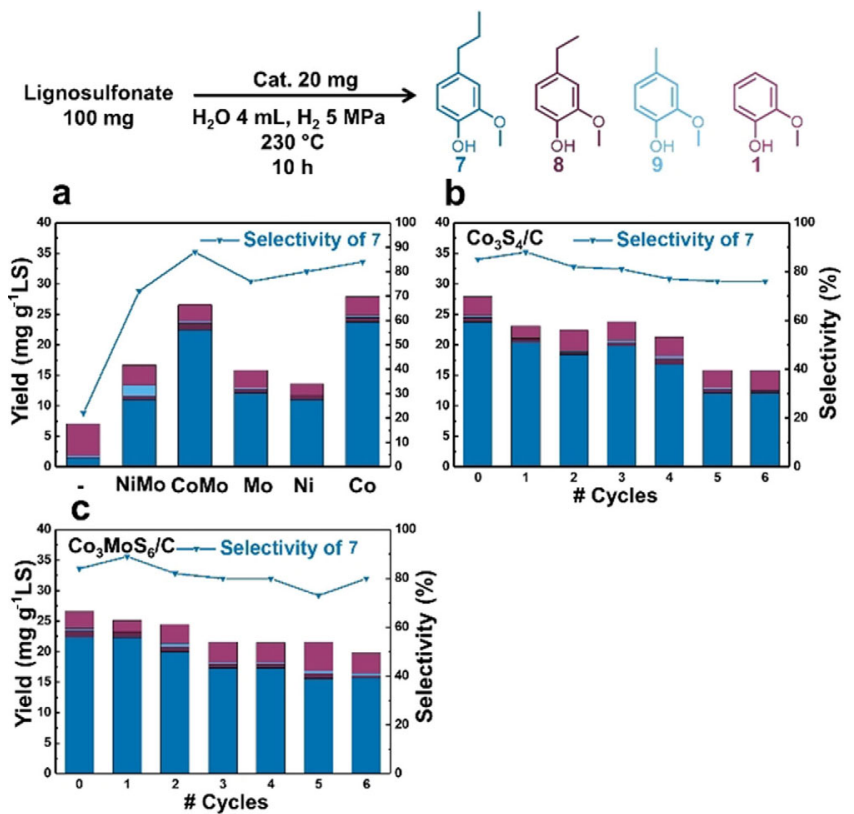

Figure 5. (a) Hydrogenolysis of LS with different catalysts. (b, c) Recycling experiments with the $\mathrm{Co}_{3} \mathrm{~S}_{4} / \mathrm{C}$ and $\mathrm{Co}_{3} \mathrm{MoS}_{6} / \mathrm{C}$ catalysts, respectively.

prise guaiacyl- $(\mathrm{G})$-derived monomers (the major monomer in softwood lignin) and differ by the alkyl chain length. A 2D heteronuclear single quantum coherence (HSQC) NMR spectrum of LS did not reveal any traces of the syringyl unit (Figure $\mathrm{S} 8$ in the Supporting Information). Upon using beech sawdust as substrate, a mixture of 4-propylguaiacol and 4-propylsyringol was obtained with no sign of propanol-substituted monomers. Therefore, the catalysts appear to be selective towards alkylsubstituted monomers. It should be noted that the selectivity to four main products is unusual because lignins usually afford large numbers of different products following their catalytic degradation. The stability of the $\mathrm{CO}_{3} \mathrm{~S}_{4} / \mathrm{C}$ and $\mathrm{CO}_{3} \mathrm{MoS}_{6} / \mathrm{C}$ catalysts was assessed in recycling experiments (Figure $5 \mathrm{~b}, \mathrm{c}$ ), with the bimetallic-sulfide catalyst appearing to be slightly more stable than the monometallic catalyst; however, both catalysts are reasonably stable for this challenging process. Presumably, the Mo in the $\mathrm{CO}_{3} \mathrm{MoS}_{6} / \mathrm{C}$ catalyst favors the stabilization by enhancing the stability of the $\mathrm{Co}-\mathrm{S}$ bonds. ${ }^{[47]}$ To assess the integrity of the $\mathrm{Co}_{3} \mathrm{~S}_{4} / \mathrm{C}$ and $\mathrm{Co}_{3} \mathrm{MoS}_{6} / \mathrm{C}$ catalysts, TEM (Figures $\mathrm{S} 10$ and S11 in the Supporting Information) and XPS (Figure S12 in the Supporting Information) studies were performed after the recycling experiments, that is, after the seventh cycle. The structure and dispersion of the metals remained similar to that of the fresh catalyst, and no sign of aggregation was apparent, suggesting that the catalysts are resistant to leaching owing to the mechanism hypothesized above. However, the EDX mapping revealed the presence of $\mathrm{Na}^{+}$ions (derived from the LS substrate), which are presumably adsorbed into the pores of the carbon support during reaction. The accumulation of $\mathrm{Na}^{+}$ ions in the support may account for the slight deactivation of the catalysts over time.

\section{Conclusions}

A series of sulfur-tolerant, highly selective hydrogenolysis catalysts were obtained by using lignosulfonate (LS) as precursor/ support material for single-atom/small-cluster or nanoparticle catalysts depending upon the metal(s) used. Additionally, to avoid hydrogenation of aromatic rings during the hydrogenolysis process (favored by nanoparticles), the metals were dispersed with $\mathrm{Mg}(\mathrm{OH})_{2}$. Although small nanoparticles were formed with the Ni-based catalysts, the entire series of catalysts did not appear to catalyze arene hydrogenation. Studies with the model substrate 2-(2-methoxyphenoxy)-1-phenylethanol showed that the bimetallic $\mathrm{NiMoS}_{3} / \mathrm{C}$ catalyst is more selective than the other catalysts and avoids condensation of the products. Although the $\mathrm{Co}_{3} \mathrm{~S}_{4} / \mathrm{C}$ catalysts are less selective with the model compound, they exhibit the highest activity with LS substrate. Importantly, quantitative selectivity towards guaiacyl monomers is achieved, and the catalyst favors the formation of 4-propylguaiacol with $84 \%$ selectivity. The use of LS prevents the metals from leaching owing to a sacrificial/compensation mechanism, and the presence of Mo as a second metal appears to enhance this stabilization by augmenting the Co-S bond strength. ${ }^{[47]}$ Overall, we demonstrated that an inexpensive catalyst comprising well-dispersed earth-abundant cobalt anchored on a carbon support derived from LS can be used to depolymerize LS with high selectivity in water in the absence of additional additives.

\section{Experimental Section}

\section{Materials}

2-(2-Methoxyphenoxy)-1-phenylethanol (MPP-ol) was synthesized according to a literature method ${ }^{[55]}$ and characterized by NMR spectroscopy (Figure S1 in the Supporting Information). Sodium lignosulfonate was purchased from TCI (L0098, Lot: V3G6G), alkali lignin was purchased from Sigma-Aldrich, Russia LS was purchased from Xingzhenghe Chemical Factory Co. Ltd. (Shenyang, China) and dealkalized lignin was purchased from J\&K China Chemical Ltd (Beijing, China). All other chemicals were obtained from Acros or Sigma-Aldrich and used without further purification. 


\section{Catalyst synthesis}

LS $(600 \mathrm{mg})$ and the appropriate metal acetate salt(s) [0.5 or $0.25 \mathrm{mmol}$ based on the metal in the acetate salt(s)] in methanol $(120 \mathrm{~mL})$ were sonicated for $30 \mathrm{~min}$. Next, $\mathrm{Mg}(\mathrm{OH})_{2}(3 \mathrm{~g}, 52 \mathrm{mmol})$ was added, and the solution was sonicated for an additional $30 \mathrm{~min}$. The resulting suspension was heated to reflux for $6 \mathrm{~h}$ at $60^{\circ} \mathrm{C}$. The reaction mixture was cooled to RT, the solvent was removed under reduced pressure, and the resulting powder was calcined at $700^{\circ} \mathrm{C}$ under an $\mathrm{N}_{2}$ atmosphere for $140 \mathrm{~min}$. After cooling to room temperature, the powder was stirred in nitric acid $(80 \mathrm{~mL}$, $1 \mathrm{M})$ for $2 \mathrm{~h}$ to remove the $\mathrm{MgO}$ and $\mathrm{Na}_{2} \mathrm{O}$ residues. The catalyst was washed with deionized water $(3 \times 100 \mathrm{~mL})$ and dried under reduced pressure at $60^{\circ} \mathrm{C}$. The other Co-based sulfide catalysts obtained from alkali lignin, Russia LS, and dealkalized lignin were prepared by using a similar procedure to that used to prepare the $\mathrm{CO}_{3} \mathrm{~S}_{4} / \mathrm{C}$ catalyst, except the lignosulfonate $(\mathrm{TCl})$ was replaced by alkali lignin $\left(\mathrm{CO}_{3} \mathrm{~S}_{4} / \mathrm{C}-\mathrm{A}\right)$, Russia $\mathrm{LS}\left(\mathrm{Co}_{3} \mathrm{~S}_{4} / \mathrm{C}-\mathrm{R}\right)$, or dealkalized lignin $\left(\mathrm{CO}_{3} \mathrm{~S}_{4} / \mathrm{C}-\mathrm{DA}\right)$, respectively.

\section{Catalyst characterization}

The surface area and pore volume were analyzed by $\mathrm{N}_{2}$ physisorption at $77 \mathrm{~K}$ by using a Micromeritics ASAP 2000M apparatus. $\mathrm{NH}_{3}-$ TPD was used to determine the acid properties of the catalysts (Micromeritics Pulse Chemisorb 2700 instrument equipped with a thermal conductivity detector). ICP-AES was used to determine the metal and sulfur content (Nexlon 350, PerkinElmer). XRD patterns were recorded on a Bruker Nonius Apex II Advance X-ray diffractometer equipped with a $\mathrm{MoK}_{\alpha}$ radiation. TEM was performed on an FEl Talos instrument operated at $200 \mathrm{kV}$ high tension. Atomic resolution imaging measurements were performed on an FEl Titan Themis $60-300$ operated at $200 \mathrm{kV}$ with an aberration-corrected electron probe and using the HAADF-STEM mode. EDX mapping was used for elemental characterization. XPS was measured on a $\mathrm{PHI}$ Versa Probe II scanning X-ray electron spectrometer with $\mathrm{AlK}_{\alpha}$ $\mathrm{X}$-ray source; the curve fitting was performed by the PHI Multipak software.

\section{Hydrogenolysis of 2-(2-methoxyphenoxy)-1-phenylethanol}

MPP-ol $(0.1 \mathrm{mmol})$ and the catalyst $(10 \mathrm{mg})$ were dispersed in deionized water $(2 \mathrm{~mL})$ under sonication $(700 \mathrm{~Hz}, 1 \mathrm{~min})$. Then, the reaction mixture was inserted in an autoclave (Parr, $75 \mathrm{~mL}$ ) and pressurized with $\mathrm{H}_{2}(1 \mathrm{MPa})$. The autoclave was heated at the desired temperature $\left(150-180^{\circ} \mathrm{C}\right)$ for $5 \mathrm{~h}$. After reaction, the products were extracted with ethyl acetate $(2 \times 5 \mathrm{~mL})$, and the catalyst was recovered by centrifugation ( $6000 \mathrm{rpm} .2 \mathrm{~min}$.). $\mathrm{H}_{2} \mathrm{~S}$ was detected by bubbling the gas after the reaction into a $\mathrm{Pb}(\mathrm{OAc})_{2}$ solution. The products were analyzed by using an Agilent 7890B GC-MS equipped with an Agilent $7000 \mathrm{C} \mathrm{GC/MS}$ triple-quad detector and a capillary column from Agilent $(30 \mathrm{~m} \times 0.25 \mathrm{~mm} \times 0.25 \mu \mathrm{m})$ with a flame ionization detector (FID). For quantification, dimethyl phthalate was used as the standard. See Figure S13 in the Supporting Information for a representative chromatogram with each compound assigned and their corresponding mass spectra.

\section{Hydrogenolysis of LS}

LS $(100 \mathrm{mg})$ and the catalyst $(20 \mathrm{mg})$ were dispersed in deionized water $(4 \mathrm{~mL})$, inserted in an autoclave (Parr, $75 \mathrm{~mL})$, and pressurized with $\mathrm{H}_{2}(5 \mathrm{MPa})$. Then, the autoclave was heated to $230^{\circ} \mathrm{C}$. After $10 \mathrm{~h}$, the reactor was cooled to room temperature, and the pressure was released. The products were extracted with ethyl acetate $(2 \times 5 \mathrm{~mL})$, and the catalyst was recovered by centrifugation (6000 rpm, $2 \mathrm{~min}$.). The products were analyzed by an Agilent 7890B GC-MS equipped with an Agilent 7000C GC/MS triple-quad detector and a capillary column from Agilent $(30 \mathrm{~m} \times 0.25 \mathrm{~mm} \times$ $0.25 \mu \mathrm{m}$ ) with an FID. For quantification, dimethyl phthalate was used as the standard.

\section{Acknowledgements}

We thank the Swiss National Science Foundation, the European Research Council (681292), Natural Science Foundation of China (21736003), and Oversea Study Program of Guangzhou Elite Project for financial support. We also thank the Interdisciplinary Center for Electron Microscopy at EPFL assistance in electron microscopic measurements and XPS, Dr. Wu Lan, Florent Héroguel, and Prof. Jeremy Luterbacher (EPFL) for the $\mathrm{N}_{2}$ adsorption-desorption measurements, and Weiyan Ni (EPFL) for the XRD analysis.

\section{Conflict of interest}

The authors declare no conflict of interest.

Keywords: biomass valorization - guaiacyl monomers hydrogenolysis $\cdot$ lignosulfonate $\cdot$ sulfide

[1] J. Zakzeski, P. C. A. Bruijnincx, A. L. Jongerius, B. M. Weckhuysen, Chem. Rev. 2010, 110, 3552-3599.

[2] G. Liu, A. W. Robertson, M. M.-J. Li, W. C. H. Kuo, M. T. Darby, M. H. Muhieddine, Y.-C. Lin, K. Suenaga, M. Stamatakis, J. H. Warner, S. C. E. Tsang, Nat. Chem. 2017, 9, 810-816.

[3] N. D. Patil, N. Yan, Catal. Commun. 2016, 84, 155-158.

[4] S. Brethauer, C. E. Wyman, Bioresour. Technol. 2010, 101, 4862-4874.

[5] S. Dutta, S. De, B. Saha, M. I. Alam, Catal. Sci. Technol. 2012, 2, 2025 2036.

[6] R. Xing, W. Qi, G. W. Huber, Energy Environ. Sci. 2011, 4, 2193.

[7] C. Li, X. Zhao, A. Wang, G. W. Huber, T. Zhang, Chem. Rev. 2015, 115, $11559-11624$.

[8] A. K. Deepa, P. L. Dhepe, ACS Catal. 2015, 5, 365-379.

[9] J. Hu, Q. Zhang, D.-J. Lee, Bioresour. Technol. 2018, 247, 1181-1183.

[10] I. Kilpeläinen, H. Xie, A. King, M. Granstrom, S. Heikkinen, D. S. Argyropoulos, J. Agric. Food Chem. 2007, 55, 9142-9148.

[11] T. Aro, P. Fatehi, ChemSusChem 2017, 10, $1861-1877$

[12] M. V. Galkin, J. S. M. Samec, ChemSusChem 2016, 9, 1544-1558.

[13] S. Baumberger, C. Lapierre, B. Monties, D. Lourdin, P. Colonna, Ind. Crops Prod. 1997, 6, 253-258.

[14] A. Kalliola, T. Vehmas, T. Liitiä, T. Tamminen, Ind. Crops Prod. 2015, 74, $150-157$.

[15] N. G. Darestani, A. Tikka, P. Fatehi, Polymers 2018, 10, 928.

[16] X. Ouyang, X. Qiu, H. Lou, D. Yang, Ind. Eng. Chem. Res. 2006, 45, $5716-$ 5721.

[17] N. Alwadani, P. Fatehi, Carbon Resour. Convers. 2018, 1, 126-138.

[18] X. Qiu, W. Zeng, W. Yu, Y. Xue, Y. Pang, X. Li, Y. Li, ACS Sustainable Chem. Eng. 2015, 3, $1551-1557$.

[19] K. Guan, Q. Liu, Y. Ji, M. Zhang, Y. Wu, J. Zhao, G. Liu, W. Jin, ChemSusChem 2018, 11, 2315-2320.

[20] L. J. Konwar, A. Samikannu, P. Mäki-Arvela, D. Boström, J.-P. Mikkola, Appl. Catal. B 2018, 220, 314-323.

[21] G. Milczarek, O. Inganäs, Science 2012, 335, 1468-1471.

[22] S. Sun, R. Bai, Y. Gu, Chem. Eur. J. 2014, 20, 549-558.

[23] S. Liu, Z. Lin, Z. Cai, J. Long, Z. Li, X. Li, Bioresour. Technol. 2018, 264, $382-386$. 
[24] L. Li, L. Huang, R. J. Linhardt, N. Koratkar, T. Simmons, Sustainable Energy Fuels 2018, 2, 422-429.

[25] M. B. Hocking, J. Chem. Educ. 1997, 74, 1055-1059.

[26] H. R. Bjørsvik, F. Minisci, Org. Process Res. Dev. 1999, 3, 330-340.

[27] M. Fache, B. Boutevin, S. Caillol, ACS Sustainable Chem. Eng. 2016, 4 $35-46$.

[28] Q. Song, F. Wang, J. Xu, Chem. Commun. 2012, 48, 7019-7021.

[29] R. Ma, Y. Xu, X. Zhang, ChemSusChem 2015, 8, 24-51.

[30] C. H. Bartholomew, P. K. Agrawal, J. R. Katzer, Adv. Catal. 1982, 31, 135242.

[31] R. Shu, Q. Zhang, Y. Xu, J. Long, L. Ma, T. Wang, P. Chen, Q. Wu, RSC Adv. 2016, 6, 5214-5222.

[32] A. Centeno, E. Laurent, B. Delmon, J. Catal. 1995, 154, 288-298.

[33] A. L. Jongerius, R. Jastrzebski, P. C. A. Bruijnincx, B. M. Weckhuysen, J. Catal. 2012, 285, 315-323.

[34] V. N. Bui, D. Laurenti, P. Delichère, C. Geantet, Appl. Catal. B 2011, 101, $246-255$.

[35] J. Shabtai, N. K. Nag, F. E. Massoth, J. Catal. 1987, 104, 413-423.

[36] E. Laurent, B. Delmon, J. Catal. 1994, 146, 281 - 291.

[37] C. R. Kumar, N. Anand, A. Kloekhorst, C. Cannilla, G. Bonura, F. Frusteri, K. Barta, H. J. Heeres, Green Chem. 2015, 17, $4921-4930$.

[38] C. Zhang, J. Lu, X. Zhang, K. MacArthur, M. Heggen, H. Li, F. Wang, Green Chem. 2016, 18, 6545-6555.

[39] M. Huuska, J. Rintala, J. Catal. 1985, 94, 230-238.

[40] M. J. Ledoux, O. Michaux, G. Agostini, P. Panissod, J. Catal. 1986, 102, $275-288$.

[41] M. Ferrari, R. Maggi, B. Delmon, P. Grange, J. Catal. 2001, 198, 47-55.

[42] M. Breysse, P. Afanasiev, C. Geantet, M. Vrinat, Catal. Today 2003, 86, 516.
[43] M. Kouzu, Y. Kuriki, F. Hamdy, K. Sakanishi, Y. Sugimoto, I. Saito, Appl. Catal. A 2004, 265, 61-67.

[44] M. Ferrari, S. Bosmans, R. Maggi, B. Delmon, P. Grange, Catal. Today 2001, 65, 257- 264.

[45] M. Ferrari, B. Delmon, P. Grange, Microporous Mesoporous Mater. 2002, $56,279-290$.

[46] W. Liu, L. Zhang, W. Yan, X. Liu, X. Yang, S. Miao, W. Wang, A. Wang, T. Zhang, Chem. Sci. 2016, 7, 5758-5764.

[47] A. Travert, H. Nakamura, R. A. Van Santen, S. Cristol, J.-F. F. Paul, E. Payen, J. Am. Chem. Soc. 2002, 124, 7084-7095.

[48] S. Ni, X. Yang, T. Li, J. Mater. Chem. 2012, 22, 2395-2397.

[49] H. Geng, S. F. Kong, Y. Wang, J. Mater. Chem. A 2014, 2, 15152-15158.

[50] Q. Liu, J. Zhang, CrystEngComm 2013, 15, 5087-5092.

[51] J. Yang, X. Duan, W. Guo, D. Li, H. Zhang, W. Zheng, Nano Energy 2014, $5,74-81$.

[52] D. L. Legrand, H. W. Nesbitt, G. M. Bancroft, Am. Mineral. 1998, 83, $1256-1265$.

[53] A. K. Deepa, P. L. Dhepe, RSC Adv. 2014, 4, 12625-12629.

[54] P. J. Dyson, Dalton Trans. 2003, 2964-2974.

[55] M. Wang, J. Lu, X. Zhang, L. Li, H. Li, N. Luo, F. Wang, ACS Catal. 2016, 6, $6086-6090$.

Manuscript received: March 8, 2019

Revised manuscript received: April 30, 2019

Accepted manuscript online: April 30, 2019

Version of record online: $\mathbf{\square} \mathbf{\square}, 0000$ 


\section{FULL PAPERS}

S. Liu, A. P. van Muyden, L. Bai, X. Cui,

Z. Fei, X. Li,* X. Hu, * P. J. Dyson*

Metal-Sulfide Catalysts Derived from Lignosulfonate and their Efficient Use in Hydrogenolysis

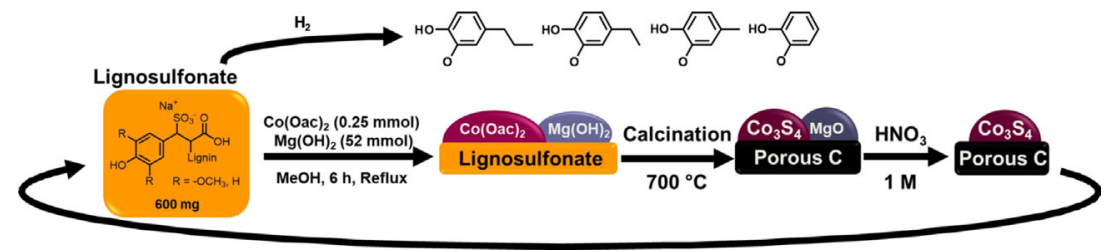

Hydrogenolysis catalysts: Lignosulfonate is used as precursor to form sulfurtolerant catalysts. The catalysts are sucnate into guaiacyl monomers by cleaving the $\mathrm{C}-\mathrm{O}$ bonds without additives. The catalysts operate in water and can be recycled and reused multiple times. 